\title{
Comparative analysis of changes in leaf area index in different wheat genotypes exposed to high temperature stress by late sown condition
}

\author{
Kamla Dhyani, Alok Shukla*, R.S. Verma \\ Technology, Pantnagar (Uttrakhand), INDIA \\ *Corresponding author. E-mail: Dhyani.k@rediffmail.com \\ Received: August 14, 2016; Revised received: June 15, 2017; Accepted: November 3, 2017
}

Department of Plant Physiology and Department of Agronomy, G.B. Pant University of Agricultural Science and

\begin{abstract}
High temperature stress during grain-filling period is one of the major environmental constraints limiting the grain yield of wheat in India. Crop growth response and relative performance of yield components of 12 wheat (Triticum aestivum) genotypes were studied in two date of sowing in crop research center (Pantnagar) to identify the causes of yield reduction in wheat particularly Leaf Area Index and its impact in yield loss and other tolerance mechanism and comparative study of LAl and yield attributes to identify the genotype for high temperature tolerance in late sown condition. The higher temperature enhanced plant growth, flowering, and maturation which ultimately effects the crop performance in case of yield (Leaf Area Index, grain weight/spike and test weight were drastically reduced in time under high temperature. Out of 12 diverse genotypes namely HI 1539, DBW 14, HW 5021, HS 240, PBW-574, Raj 4101, Lok 54, Raj 3765, WH 1021, K-0-307, HW 2045 and HI1544,four were (Lok54, Raj3765, HI1539 and HI1544 ) were characterized as high temperature tolerant based on their relative performance in leaf area index, grain yield and heat susceptibility index. Leaf area Index studies in context to heat stress in wheat is least studied area in heat tolerance research in wheat (Triticum aestivum), in the present study LAl is used as a screening tool for heat tolerance and effect of LAI in wheat yield.
\end{abstract}

Keywords: Genotype, Growth, HSI, Leaf area index, Tolerant yield

\section{INTRODUCTION}

The temperature range for the growth and development of spring-wheat is around $20^{\circ} \mathrm{C}-25^{\circ} \mathrm{C}$, The average global temperature is reported to be increasing at a rate of $0.18{ }^{\circ} \mathrm{C}$ every decade and global wheat production is estimated to fall by $6 \%$ for each ${ }^{\circ} \mathrm{C}$ of further temperature increase and become more variable over space and time (Assenge et al., 2015).

A substantial increase in world food supply of 70 $100 \%$ is required to feed an estimated 9 billion people by 2050 (Godfray et al., 2010) but when the temperature often rises above $30^{\circ} \mathrm{C}$ before the physiological maturity of wheat in many wheat growing countries including India, causes deleterious effect on the grain yield . Extreme events occurring during the summer period would have the most dramatic impact on plant productivity; however, there has been little research conducted to document these effects as found by Kumudini et al. (2014)

Recent review by Barlow et al. (2015) on the effect of temperature extremes on wheat (Triticum aestivum L.) revealed that temperature caused reduction in grain number and reduced duration of the grain-filling period. Early senescence due to high temperature and reducing leaf area may be one of the main causes of yield loss in late-sown condition in India. Faster devel- opment of non-perennial crops results in a shorter life cycle resulting in smaller plants, shorter reproductive duration, and lower yield potential.( Hatfield, 2015). Faster development due to high temperature leads to early senescence or reducing photosynthetic leaf area which ultimately reduce the crop canopy during the reproductive stage. The rapid leaf senescence ultimately resulted for reducing grain feeling duration, less productive tillers/plant, which is one of the major causes of yield loss in wheat. (Kumari et al., 2007). However, crop response to high temperatures varied with variation of temperatures, duration of exposure, crop growth stages, and also due to the level of crop tolerance. The present study deals with the effect of sowing dates on the foliage density (canopy architecture) on crop growth stages, relative performance of yield components and yield of twelve diverse wheat genotypes in different sowing dates in order to identify the genotypes relatively tolerant to high temperature at whole plant level on the basis of the leaf area index, HSI and crop productivity.

The main purposes of this study were to investigate genotypic variation in Leaf Area Index and its effect on heat tolerance behaviour of wheat (Triticum aestivum), and to examine the changes in leaf area index (LAI) and its correlation with yield attributing characters. 


\section{MATERIALS AND METHODS}

The experiments were conducted under two sowing dates in two crop season. The present study deals with the impact of heat stress on canopy architecture and its relevance with the heat tolerance of 12 genotypes of wheat (Triticum aestivum). An experiment was conducted at the Norman E Bourlog Crop Research Center of G. B. Pant University of Agriculture \& Technology, Pantnagar, during the rabi season.There were two date of sowing (20 Nov) and (23 December 2011).

Plant material: Twelve wheat genotypes were obtained from the Directorate of wheat research (Kernal Haryana), which was a part of All India Coordinated project on Heat Tolerance of wheat.

Genotypes are as follows HI 1544, DBW 14, HW 5021, HS 240, PBW-574, Raj 4101,Lok 54,Raj 3765,WH 1021,K-0-307, HW 2045 ,HI-1544 out of them some are tolerant some are susceptible. All genotypes wre arranged in randomized block design in field condition.

Plant canopy analysis: To measure the leaf area index Plant Canopy Analyzer (LAI-2000, LI-COR, USA) was used. This instrument is helpful in directly recording foliage density (Leaf area index), mean tilt angle (an indicator of leaf angle) and gap fraction (proportion of area not covered by crop) in a crop canopy, The LAI2000 calculates LAI and other canopy structure attributes from solar radiation measurements made with a wide-angle optical sensor. These observations were recorded in net plot area at 30, 50, 70, 90, 110 days after sowing.

Heat susceptibility index: Heat susceptibility index (S) was calculated for grain yield using the following equation as described by Fisher and Maurer (1978), S $=(1-\mathrm{Y} / \mathrm{Yp}), 1(1-\mathrm{X} / \mathrm{Xp})$ Where, $\mathrm{Y}$ is mean grain yield of a genotype under stress environment (high temperature), $\mathrm{Yp}$ is mean yield of the same genotype under stress free environment (optimum temperature), $\mathrm{X}$ is mean $\mathrm{Y}$ of all genotypes, and $\mathrm{Xp}$ is mean $\mathrm{Yp}$ of all genotypes. If $S<0.5$, the crop is highly stress tolerant, if $\mathrm{S}>0.5<1.0$, moderately stress tolerant, and if $\mathrm{S}>1.0$, susceptible to stress. All the data were statistically analyzed and means were compared by least significant difference (LSD) test at 5\% level of probability.

Yield attributes: Crop was harvested at third week of April in each experimental year. At physiological maturity the data regarding grain yield, grain weight and test weight and biological yield were estimated by standard agronomical procedures. Grains obtained from each plot were weighted and grain yield was obtained in terms of t ha- 1 and data were analysed statistically by using Fisher's analysis of variance technique.

Statistical analysis: Results were analyzed by oneway ANOVA to identify significant differences between the groups and their significance levels ( $p<$
$0.05)$ were determined.

\section{RESULTS AND DISCUSSION}

The data obtained on canopy architecture recorded at 30, 50, 70 and 90 days after sowing are presented in Table-1, The leaf area indices recorded at different stages were significantly at (5\% level of significance) reduced through out the study due to delay in sowing, genotypic difference also significant at all the stages except 70 days after sowing. The interaction between sowing date and genotype was significant at all the stages except 70 days after sowing. Delay in sowing or increasing temperature declined the leaf area index. Data on leaf area index at 30 days after sowing shows early ground cover, and rapid ground cover and it is an important traits, it characterizes the capacity of genotypes to develop leaf area or above ground biomass. Genotype HI1544, Lok54, Raj 3765, HI1539, HW 2045 had maximum leaf area index ( 30, 50, 70 and 90 days after sowing) With the present investigation it can be stated that Leaf area index values of at least 3.54.5 in the reproductive stages are required for maximum potential yield in Wheat. Genotype Lok54, HI1539, Raj3765 and Raj4101 performed well by late showing. Leaf area (LA) of wheat largely depends on the diversity of genotype, plant growth stage and air temperature, delay in sowing significantly reduced the leaf area index. On an average, $40 \%, 16 \%, 7 \%$, and $24 \%$ per cent reduction in leaf area index was recorded at 30, 50, 70 and 90 days after sowing. Paul (2016) also reported that there was a negative effect of heat on leaf area index on crop plants due to late sowing of crop. Ihsan et al. (2016) also reported that growth and leaf area of all wheat varieties gradually decreased with delay in sowing. Genotypic difference in green leaf area duration and stay green character in response to heat stress is also reported by (Kumar al et., 2010). Grain yield which is the important agronomic traits for a crop is highly effected by the date of sowing or high temperature, Maximum grain yield is obtained by Raj

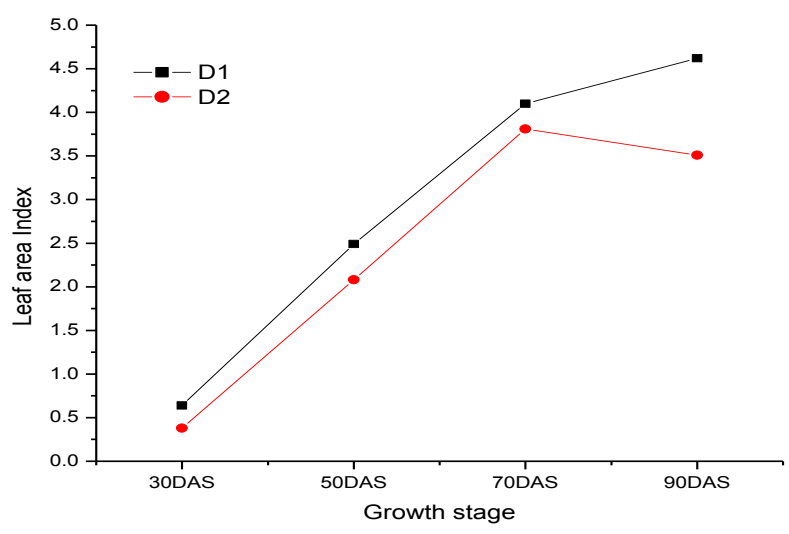

Fig. 1. Changes in leaf area index at different stages of growth in Triticun aestivum under timely and late sown condition. 
Table 1. Effect of sowing dates on leaf area index in different wheat genotypes.

\begin{tabular}{lcccccccc}
\hline \multirow{2}{*}{ Genotypes } & \multicolumn{2}{c}{ LAI 30 DAS } & \multicolumn{2}{c}{ LAI 50 DAS } & \multicolumn{2}{c}{ LAI 70 DAS } & \multicolumn{2}{c}{ LAI 90 DAS } \\
\cline { 2 - 9 } & 20 Nov & 23 Dec & 20 Nov & 23 Dec & 20 Nov & 23 Dec & 20 Nov & 23 Dec \\
\hline HI 1539 & 0.58 & 0.32 & 2.44 & 2.41 & 4.24 & 4.06 & 4.72 & 3.73 \\
DBW 14 & 0.50 & 0.32 & 2.21 & 2.17 & 3.88 & 3.87 & 3.93 & 3.56 \\
HW 5021 & 0.53 & 0.29 & 2.47 & 1.74 & 3.80 & 3.19 & 3.96 & 3.60 \\
HS 240 & 0.83 & 0.37 & 2.23 & 2.08 & 4.06 & 3.94 & 4.54 & 2.96 \\
PBW-574 & 0.64 & 0.34 & 2.40 & 1.35 & 4.21 & 3.44 & 4.47 & 3.39 \\
Raj 4101 & 0.84 & 0.81 & 2.16 & 2.08 & 3.88 & 3.80 & 4.83 & 3.36 \\
Lok 54 & 0.78 & 0.74 & 3.08 & 2.76 & 4.36 & 3.96 & 4.38 & 3.82 \\
Raj 3765 & 0.94 & 0.65 & 2.91 & 2.24 & 4.24 & 3.78 & 4.68 & 3.45 \\
WH 1021 & 0.43 & 0.38 & 2.43 & 2.56 & 4.15 & 3.64 & 4.80 & 3.77 \\
K-0-307 & 0.60 & 0.30 & 2.60 & 1.36 & 4.60 & 3.78 & 5.82 & 4.5 \\
HW 2045 & 0.48 & 0.30 & 2.30 & 2.00 & 3.88 & 3.90 & 4.47 & 3.79 \\
HI-1544 & 0.71 & 0.42 & 2.65 & 2.26 & 3.93 & 4.39 & 4.70 & 3.17 \\
& S.Em.. \pm & CD at 5\% & S.Em.. \pm & CD at 5\% & S.Em. \pm & CD at 5\% & S.Em. E & CD at 5\% \\
Dates & 0.002 & 0.079 & 0.18 & 0.52 & 0.30 & 0.61 & 0.21 & 0.61 \\
Genotypes & 0.002 & 0.087 & 0.20 & 0.74 & 0.34 & 0.90 & 0.24 & .36 \\
\hline
\end{tabular}

Table 2. Effect of sowing dates on grain yield, harvest index, grain weight and test weight different wheat genotypes at 30,50 , 70,90 days after sowing during year 2011 .

\begin{tabular}{lllllllll}
\hline \multirow{2}{*}{ Genotypes } & \multicolumn{2}{l}{ Grain yield (t/Ha) } & \multicolumn{2}{c}{ Harvest Index } & \multicolumn{2}{c}{ Grain Weight / } & spike & \multicolumn{2}{c}{ Test Weight } \\
\cline { 2 - 9 } & 20 Nov & 23 Dec & 20 Nov & 23 Dec & 20 Nov & 23 Dec & 20 Nov & 23 Dec \\
\hline HI 1539 & 5.37 & 3.31 & 35.76 & 51.05 & 2.03 & 1.40 & 46.10 & 41.80 \\
DBW 14 & 4.7 & 2.71 & 41.39 & 34.21 & 1.77 & 1.31 & 41.67 & 33.62 \\
HW 5021 & 4.65 & 2.62 & 39.69 & 25.47 & 2.18 & 1.12 & 40.25 & 32.28 \\
HS 240 & 3.69 & 1.68 & 29.49 & 18.07 & 2.00 & 1.12 & 35.07 & 29.48 \\
PBW-574 & 4.67 & 3.36 & 36.86 & 31.07 & 1.77 & 1.42 & 35.55 & 32.77 \\
Raj 4101 & 5.05 & 3.47 & 45.94 & 44.45 & 2.07 & 1.32 & 45.18 & 30.87 \\
Lok 54 & 4.30 & 3.70 & 45.70 & 44.18 & 1.78 & 1.62 & 50.70 & 48.57 \\
Raj 3765 & 4.95 & 3.15 & 38.70 & 28.86 & 1.51 & 1.31 & 41.05 & 39.00 \\
WH 1021 & 4.54 & 3.31 & 44.41 & 41.92 & 2.14 & 1.38 & 45.53 & 37.97 \\
K-0-307 & 3.67 & 2.84 & 30.81 & 27.61 & 1.54 & 1.25 & 42.93 & 37.25 \\
HW 2045 & 4.45 & 3.50 & 35.79 & 29.16 & 1.82 & 1.44 & 44.40 & 39.98 \\
HI-1544 & 4.8 & 3.32 & 51.05 & 41.60 & 1.43 & 1.02 & 42.95 & 40.50 \\
\hline
\end{tabular}

Table 3. Heat susceptibility indices for different yield parameters in different Triticum aestivum genotypes.

\begin{tabular}{lcccc}
\hline \multirow{2}{*}{ Genotypes } & \multicolumn{4}{c}{ Heat susceptibility indices } \\
\cline { 2 - 5 } & Grain yield (q/ha) & Grain weight (g) /spike & Fertile spikelet/spike & 1000 grain weight (g) \\
\hline HI 1539 & 1.068 & 1.071 & 2.376 & 0.858 \\
DBW 14 & 0.780 & 0.897 & 6.581 & 1.020 \\
HW 5021 & 1.408 & 1.678 & 3.948 & 1.040 \\
HS 240 & 1.757 & 1.519 & -1.248 & 1.330 \\
PBW-574 & 0.905 & 0.682 & 3.007 & 0.411 \\
Raj 4101 & 1.009 & 1.250 & -2.981 & 0.650 \\
Lok 54 & 0.533 & 0.310 & 2.847 & 0.259 \\
Raj 3765 & 0.905 & 0.457 & 0.333 & 0.649 \\
WH 1021 & 0.802 & 1.226 & 2.178 & 1.290 \\
K-0-307 & 0.730 & 0.650 & -2.406 & 1.170 \\
HW 2045 & 0.689 & 0.720 & 0.307 & 0.899 \\
HI-1544 & 1.395 & 0.989 & -4.548 & 0.246 \\
\hline
\end{tabular}

4101, HI1544 and HW5021 in timely sown condition but in late sown condition Lok54, Raj 4101 and DBW140 were the good performer. These genotypes also sow optimum LAI. In case of grain weight /spike WH1021, Lok 54, Raj 4101, PBW574 showed good results. The yield loss due to high temperature is also reported by Jena (2017) due to heat stress.

The concept of HS I was given to determine the total effect of heat in terms of reduction in the grain yield, The lowest HSI was recorded in wheat genotype lok
54 followed by Raj 3765, PBW 574, HW 2045, DBW 14 and HI 1544, which shows the tolerant nature of these genotypes. HW 5021 and HS 240 were most heat susceptible in case of HSI. Heat susceptibility index for yield attributes mostly for grain weight/ spike and thousand grain weight, also can be used for screening purpose, Susceptibility index (SI) has been effectively used for measuring heat tolerance and drought tolerance in hexaploid. 


\section{Conclusion}

As global temperature increasing day by day and the yield potential of wheat is also decreasing by heat and other abiotic stress. So it became an important topic of debate that how wheat will cope up with increasing earth temperature and how low productivity will fulfil the food demand of increasing population. The selection of wheat genotypes with better grain yield and tolerance is the principal aim of wheat production. In this study, terminal heat stress caused significant changes in leaf area index, grain yield and heat susceptibility index in wheat genotype studied. Significant reductions in LAI, yield and HSI under stress conditions were observed. This study concludes that the wheat genotypes affected by prolonged heat stress are found to differ in their ability to respond, thereby tolerance, which could be useful as genetic stock to develop wheat tolerant varieties in breeding programs. During recent years, new parameters for heat stress tolerance e.g., Heat Sensitivity Index (HSI) for TKW, GFD have been developed. These parameters allow selection of best heat tolerant plant/lines in combination with physiological and biochemical approaches. Intrinsic research in this field require and multidimensional approach for heat tolerance needed. In molecular studies agronomic traits shoud be taken in concern to know the actual cause of yield reduction in wheat during high temperature condition. Leaf area index, HSI and other yield attributes may be good tool to screen wheat genotypes under terminal heat stress condition.

\section{ACKNOWLEDGEMENTS}

Authors are thankful to Director Research, G.B. Pant University of Agriculture and Technology, Pantnagar263145 (Uttarakhand) for providing research facilities and to Late Prof. Dr. Alok Shukla, Department of Plant Physiology for critical reading of the manuscript.

\section{REFERENCES}

Assenge, A., Evert, F., Martre, P., Rotter, R.P., (2015). Rising temperatures reduce global wheat production. Nature and Climate Change., 5 :143-147.

Barlow, K.M., Christy, B.P., O’Leary, G.J., Riffkin, P.A. \& Nuttal, J.G. (2015). Simulating the impact of extreme heat and frost events on wheat crop production: A review. Field Crops Research, 171:109-119.

Godfray, H.C.J., Beddington, JR., Crute, IR., Haddad, L., Lawrence, D., Muir, J.F., Pretty, J., Robinson, S., Thomas, SM., Toulmin, C., (2010). Food security: the challenge of feeding 9 billion people. Science 327: 812 818.

Hansen, J and Sato, M. (2016). Regional climate change and national responsibilities, Environ. Res. Lett. 11

Hatfield, J.L. and Prueger, J.H.. (2015). Temperature extremes: Effect on plant growth and development. Weather Clim. Extremes 10:4-10. doi:10.1016/ j.wace.2015.08.001

Ihsan,Z.M, Faithy.N.S, Saleh.M.I, Fahad.S and Ihamulladaur (2016), Wheat phonological development and growth studies as effected by drought and Late sown high temperature stress under arid environment, Frontiers in Plant Sciences.

Jena.T, Singh,R.K, Singh.M.K (2017), Mitigation measures of Wheat production under heat stress. International Journal of Agriculture Science \& Research. 7: 22502257

Kumar, U., Joshi, A., Kumari, M., Paliwal, R., Kumar, S., Röder, M. (2010) Identification of QTLs for stay green trait in wheat (Triticum aestivum L.) in the 'Chirya 'Sonalika' population. Euphytica 174: 437-445

Kumari, M., Singh, V. R., Joshi. (2007) Variation for stay green trait and its association with canopy temperature depression and yield traits under terminal heat stress in wheat; Berlin: Springer.357-63.

Kumudini, S., F.H, Andrade., Boote, K.J., Brouss, G.A, Drotzi, K.A (2014). Predicting maize phenoloy: Inter comparison of functions for developmental response to temperature. Agronomy Journal, 106: 2087-2097

Paul.S., Bose. I and Gogoi (2016) Morphological responses: Criteria for screening heat tolerance in Potato. Current Sciences, 111:1226-1231. 